\title{
AÇÕES DE \\ INTERNACIONALIZAÇÃO \\ PARA O ENSINO \\ E A PESQUISA \\ NA ÁREA \\ DE LÍNGUAS
}

\section{ACCIONES DE INTERNACIONALIZACIÓN PARA LA ENSEÑANZA Y LA INVESTIGACIÓN EN EL ÁREA DE IDIOMAS}

\author{
INTERNATIONALIZATION ACTIONS FOR TEACHING AND RESEARCH IN THE \\ LANGUAGE AREA
}

Paula Tavares Pinto*

UNESP | campus São José do Rio Preto

Daniela Nogueira de Moraes Garcia**

UNESP | campus Assis

Douglas Cunha dos Santos***

UNESP | campus Assis

RESUMO: Muitos planos estratégicos visam o crescimento na internacionalização (DE WIT et al., 2015) e mobilidade a partir da compreensão de que tais ações demandam proficiência no idioma para comunicação, intercâmbio de pesquisas, parcerias básicas e desenvolvimentos digitais. Embora universidades mantenham acordos internacionais, é fundamental que compreendam como as línguas estrangeiras são vitais para envolver estudantes e acadêmicos de forma orgânica. Objetivamos apresentar as ações com vistas à internacionalização que têm sido implementadas como forma de mapear e melhorar a proficiência linguística na Universidade

\footnotetext{
* Paula Tavares Pinto é Docente no Departamento de Letras Modernas da UNESP, S. J. do Rio Preto. Atua no Programa de Pós-Graduação em Estudos Linguísticos com os temas Estudos da Tradução, Terminologia e Ensino e Aprendizagem de Línguas. E-mail:paula.pinto@unesp.br.

** Daniela Nogueira de Moraes Garcia é Doutora em Estudos Linguísticos e docente do Departamento de Letras Modernas da UNESP, Campus de Assis. Suas áreas de interesse enfocam o ensino de línguas, tecnologias, telecolaboração e formaçãodeprofessores. E-mail: dany7garcia@gmail.com.

*** Douglas Cunha dos Santos é Graduado em Letras pela UNESP, Campus de Assis. Atua como professor-bolsista nos cursos de apoio a internacionalizaça provenientes do convênio UNESP/Santander. E-mail: douglas.cunha101@gmail.com.
} 
Estadual Paulista, instituição multicampi. Dentre tais ações, enfocaremos o mapeamento do nível de proficiência linguística dos alunos e comunidade interna, oferta de cursos e testes e ações de mobilidade internacional na própria instituição como as sessões de intercâmbio virtual em língua estrangeira ou língua franca. Os resultados apontam para uma crescente conscientização acerca da importância da proficiência linguística e ações que priorizam a globalização do Ensino Superior.

PALAVRAS-CHAVE: Plano estratégico. Internacionalização. Proficiência linguística.

RESUMEN: Muchos planes estratégicos tienen como objetivo el crecimiento en la internacionalización (DE WIT et al., 2015) y la movilidad partiendo de la comprensión de que tales acciones requieren el dominio de un idioma para la comunicación, el intercambio de investigaciones, alianzas básicas y desarrollos digitales. Aunque las universidades mantengan acuerdos internacionales, es esencial que comprendan cómo las lenguas extranjeras son vitales para la participación orgánica entre estudiantes y académicos. Nuestro objetivo es presentar las acciones dirigidas a la internacionalización que se han implementado como una forma de mapear y mejorar la competencia lingüística en la Universidad Estadual Paulista-UNESP, una institución multicampus. Nos enfocaremos en mapear el nivel de dominio del idioma de los estudiantes y la comunidad interna, ofreciendo cursos, pruebas y acciones de movilidad internacional en la propia institución, como sesiones de intercambio virtual en lengua extranjera o lengua franca. Los resultados apuntan a una conciencia creciente sobre la importancia del dominio del idioma y las acciones que priorizan la globalización de la educación superior.

PALABRAS CLAVE: Plan estratégico. Internacionalización. Competencia lingüística.

ABSTRACT: Many strategic plans aim at the growth in internationalization (DE WIT et al., 2015) and mobility based on the understanding that such actions require language proficiency for communication, research exchange, basic partnerships, and digital developments. While many universities maintain international agreements, they must understand how foreign languages are vital to organically engaging students and academics. In this work, we present actions aimed at internationalization that have been implemented as a way to map and improve linguistic proficiency at Universidade Estadual Paulista (UNESP), a multicampi institution. Among such actions, we will focus on mapping the level of language proficiency of students and the internal community, offering courses and tests and international mobility actions in the institution itself, such as virtual exchange sessions in a foreign language or lingua franca. The results point to growing awareness about the importance of language proficiency and actions that prioritize the globalization of Higher Education.

KEYWORDS: Strategic plan. Internationalization. Linguistic proficiency.

\section{INTRODUÇÃO}

Muitos planos estratégicos de universidades do mundo todo têm como foco o crescimento das ações de internacionalização e de mobilidade. Uma necessidade, muitas vezes, esquecida para facilitar este processo é o conhecimento de línguas estrangeiras. Todas as formas de mobilidade, para alunos e docentes que chegam ou para os que saem, exigem proficiência no idioma do país de destino para fins de comunicação no contexto acadêmico, para o desenvolvimento de pesquisas e escrita de artigos científicos entre os parceiros. Embora muitas destas universidades mantenham acordos internacionais de pesquisa e mobilidade, é fundamental que compreendam como as línguas estrangeiras são vitais para o envolvimento de estudantes e de acadêmicos em todos os setores da universidade.

Neste sentido, a internacionalização do Ensino Superior tem requerido mais a atenção das universidades no mundo todo, uma vez que a globalização trouxe a possibilidade de os profissionais de diferentes países competirem por melhores empregos mundialmente. Este fato tem exigido a formação de indivíduos preparados profissionalmente e culturalmente para contextos internacionais. 
De Wit et al. (2015, p. 29) definem a internacionalização como um processo de: "[...] integração de uma dimensão internacional, intercultural ou global ao propósito, funções e fornecimento do ensino pós-secundário, a fim de melhorar a qualidade da educação e da pesquisa de todos os estudantes e funcionários e de fornecer uma contribuição significativa à sociedade" ${ }^{\text {. }}$

Em tempos globalizados e impulsionados pelo advento da internet, o panorama da educação superior, principalmente das línguas estrangeiras, demanda atenção, já que os laços e ações entre países têm se mostrado potencializadores de experiências e pesquisas.

Para Behrens (2013, p.84),

[...] num mundo globalizado, que derruba barreiras de tempo e espaço, o acesso à tecnologia exige atitude crítica e inovadora, possibilitando o relacionamento com a sociedade. O desafio passa por criar e permitir uma nova ação docente na qual professor e alunos participam de um processo conjunto para aprender de forma criativa, dinâmica, encorajadora e que tenha como essência o diálogo e a descoberta.

Entendemos, assim, a necessidade de articulações dentro da universidade que abarque o processo de ensinar, de aprender diante de novos cenários e novos perfis de aprendizes.

Acerca do processo de internacionalização, Abreu-e-Lima et al. (2016, p.47) reconhecem que

O processo de internacionalização, considerado como um dos desafios da educação superior, envolve a definição de objetivos articulados com as demandas educacionais, as diretrizes curriculares, a legislação vigente, e com o Plano Nacional de Educação (PNE). De modo especial, o processo envolve também o uso de tecnologias de informação e comunicação, a formação de pessoal qualificado para Educação a Distância e a definição de programas de estímulo visando à ampliação de intercâmbios internacionais, aspectos curriculares e organizacionais. Essencialmente, envolve ainda questões linguísticas decorrentes deste processo de internacionalização, quer por intermédio de línguas estrangeiras, quer pela utilização da língua portuguesa como língua estrangeira.

Sendo assim, é possível observar a complexidade do cenário e as diversas esferas de sua implementação. É importante mencionar o Programa Ciências sem Fronteiras, de 2011, que, com propósitos de globalização e internacionalização, investiu em intercâmbios e mobilidade internacional em todas as áreas do conhecimento em ações governamentais conjuntas. Dessa forma, focando em estágios para alunos de graduação e pós-graduação, esbarrou em questões de proficiência linguística que o descontinuaram mas fomentaram a criação do Programa Inglês sem Fronteiras (IsF) e sua expansão para os outros idiomas no Idiomas sem Fronteiras. Sarmento et al. (2016) reconhecem uma crescente busca pela aprendizagem de línguas em território nacional, busca esta desencadeada pela rápida expansão da internacionalização da educação superior. Os autores apontam os supracitados programas como fruto de tal busca.

Ainda que, atualmente, em fase de remodelação dado o cenário político-nacional vigente, testemunhamos uma grande oferta de cursos de línguas ministrados em instituições brasileiras federais e estaduais, de forma presencial e on-line síncrona, pautada na formação inicial e continuada. Observou-se, pelo IsF, a constituição de uma robusta rede de compartilhamento de informações e conhecimento visando o fortalecimento de políticas linguísticas e o ensino de línguas no Brasil. Diante da grandiosidade do Programa, é importante destacar que esta rede contemplou parcerias nacionais e internacionais que vislumbraram uma visão eficiente e especializada acerca do processo de ensinar e aprender línguas estrangeiras.

Reconhecendo a importância de se mapear a proficiência linguística na universidade com vistas ao fomento da internacionalização, mobilidade e parcerias com universidades estrangeiras, o presente trabalho visa apresentar ações que têm sido implementadas para

${ }^{1}$ Tradução de " $[\ldots]$ the process of 'integrating an international, intercultural or global dimension into the purpose, functions and delivery of post-secondary education, in order to enhance the quality of education and research for all students and staff and to make a meaningful contribution to society" (DE WIT et al., 2015, p. 29) 
incentivar a internacionalização da Universidade Estadual Paulista Júlio de Mesquita Filho (UNESP), instituição multicampi no estado de São Paulo, conforme figura a seguir:

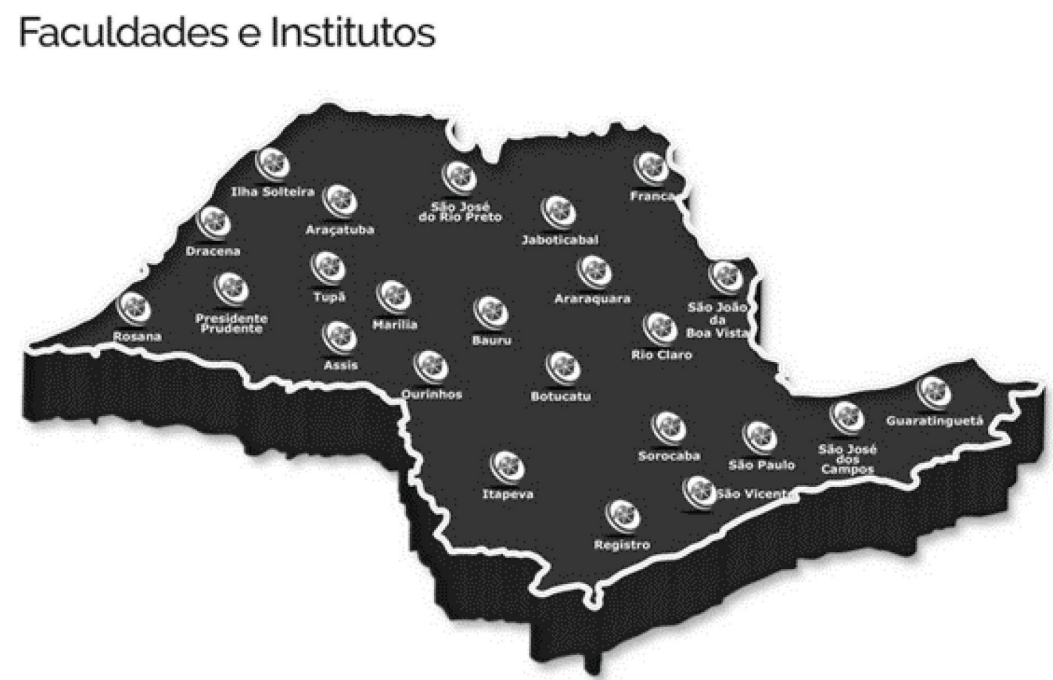

Figura 1: Campi da Unesp distribuídos em diversas cidades do Estado de São Paulo.

Fonte: Reitoria da Unesp

O fato de a universidade não estar centralizada em um campus somente torna todas as ações mais difíceis de serem implementadas. Neste sentido, temos contado com a participação dos professores e futuros professores de língua inglesa dos cursos de Letras da instituição nos cursos presenciais e on-line que estão sendo oferecidos à comunidade institucional. As ações estão diretamente ligadas ao Gabinete do Reitor, às Pró-Reitorias de Graduação e de Extensão, por meio dos Centros de Línguas, e à Assessoria de Relações Internacionais (AREX). Em razão da complexidade da implementação dos cursos nos vários campi da UNESP, as ações vêm contando com o apoio dos Centros Locais de Internacionalização situados nos 34 campi da UNESP. Para tanto, quatro docentes de língua inglesa dos cursos de Licenciatura em Letras da UNESP orientam os cursos oferecidos pelos Centros de Línguas da UNESP e acompanham o desenvolvimento das ações nas unidades, conforme Portaria 443 de criação de Comitês Regionais, a saber:

I - Comitê Regional de Araraquara - Botucatu, Sorocaba, Itapeva, São Vicente, Registro, São Paulo, Guaratinguetá e São José dos Campos;

II - Comitê Regional de São José do Rio Preto - Franca, Rio Claro, Jaboticabal, São João da Boa Vista, Ilha Solteira e Araçatuba;

III - Comitê Regional de Assis - Marília, Bauru, Presidente Prudente, Rosana, Ourinhos, Dracena e Tupã.

Apresentaremos, a seguir, as bases do plano de internacionalização da UNESP, o mapeamento da proficiência em língua inglesa da comunidade unespiana e as ações que vêm sendo realizadas como apoio e fomento à melhoria desta proficiência, como o oferecimento de cursos on-line, testes e possibilidades de intercâmbio virtual com universidades no exterior.

\section{PLANO DE INTERNACIONALIZAÇÃO E A PERCEPÇÃO LINGUÍSTICA DA UNIVERSIDADE POR MEIO DO MAPEAMENTO DE SUA COMUNIDADE}

Em 2018, a UNESP elaborou seu Plano Estratégico de Internacionalização para todos os setores da universidade. Este plano tem como foco o desenvolvimento de talentos globais, de pesquisas e de parcerias com instituições internacionais, conforme retratam os pilares da figura 2 . 


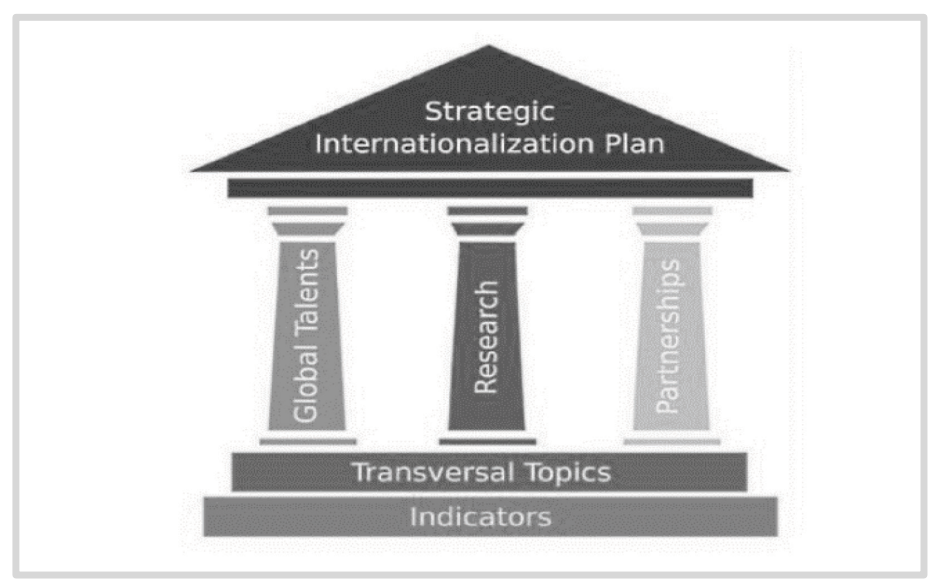

Figura 2: Plano Estratégico de Internacionalização

Fonte: Plano Estratégico de Internacionalização da Unesp (2020)

Na base dos três pilares, encontram-se as ações transversais que perpassam as pró-reitorias de graduação, pós-graduação, extensão e pesquisa e que são acompanhadas por indicadores de impacto e desenvolvimento. Conforme veremos nas seções seguintes, a língua inglesa é fundamental para que as ações de internacionalização sejam implementadas com sucesso.

O fato de a língua inglesa ser considerada língua franca (BELTA, 2020) também atende às demandas de programas de mobilidade internacional, uma vez que alunos brasileiros, em sua maioria, buscam desenvolver suas pesquisas em universidades de países de língua inglesa, como podemos visualizar na figura 3.

\begin{tabular}{|c|c|c|l|l|}
\hline $\begin{array}{c}\text { Position } \\
2017\end{array}$ & $\begin{array}{c}\text { Position } \\
2016\end{array}$ & $\begin{array}{c}\text { Position } \\
2015\end{array}$ & \multicolumn{1}{|c|}{ Country } & $\begin{array}{l}\text { Score } \\
2017\end{array}$ \\
\hline $1^{\circ}$ & $1^{\circ}$ & $1^{\circ}$ & Canada & 9194 \\
\hline $2^{\circ}$ & $2^{\circ}$ & $2^{\circ}$ & United States & 8638 \\
\hline $3^{\circ}$ & $5^{\circ}$ & $5^{\circ}$ & United Kingdom & 7742 \\
\hline $4^{\circ}$ & $3^{\circ}$ & $3^{\circ}$ & Australia & 7654 \\
\hline $5^{\circ}$ & $4^{\circ}$ & $4^{\circ}$ & Ireland & 6602 \\
\hline $6^{\circ}$ & $6^{\circ}$ & $6^{\circ}$ & New Zealand & 6356 \\
\hline $7^{\circ}$ & $7^{\circ}$ & $7^{\circ}$ & Malta & 6085 \\
\hline $8^{\circ}$ & $8^{\circ}$ & $8^{\circ}$ & South Africa & 5571 \\
\hline $9^{\circ}$ & $9^{\circ}$ & $1^{\circ}$ & Spain & 4132 \\
\hline $10^{\circ}$ & $1^{\circ}$ & $9^{\circ}$ & France & 3474 \\
\hline
\end{tabular}

Figura 3: Os dez destinos mais populares de alunos brasileiros, 2015 a 2017

Fonte: Site da Brazilian Educational \& Language Travel Association Belta (2020)

Levando-se em consideração a questão da pesquisa e da transversalidade, assim como a formação de talentos globais, a UNESP decidiu apresentar um programa que atendesse às necessidades da instituição em relação ao conhecimento da língua inglesa. Dessa forma, a universidade estaria preparando sua comunidade para participar de editais de pesquisa e mobilidade, conforme veremos na próxima seção.

\subsection{A PERCEPÇÃO LINGUÍSTICA DA UNIVERSIDADE POR MEIO DO MAPEAMENTO DE SUA COMUNIDADE}

Para a participação em programas de mobilidade e desenvolvimento de pesquisas com parceiros no exterior, as agências de fomento nacionais e internacionais, diferentemente de anos anteriores, passaram a exigir um nível de proficiência em língua estrangeira mais elevado de seus candidatos. A Coordenação de Aperfeiçoamento de Pessoal de Nível Superior (CAPES), por exemplo, que recebia atestados de proficiência emitidos por professores das próprias universidades, passou a requerer resultados de provas reconhecidas internacionalmente como as provas do Test of English as a Foreign Language (TOEFL) e International English Language Testing System (IELTS), no caso da língua inglesa. Isso se deve ao fato de que muitos alunos brasileiros, participantes de intercâmbios em 
anos anteriores manifestaram dificuldade em se comunicar em contextos acadêmicos que exigem habilidades ativas de língua estrangeira como a escrita de trabalhos de disciplinas e de relatórios científicos, assim como a apresentação oral de trabalhos vinculados aos seus cursos ou em congressos internacionais.

O programa Ciência sem Fronteiras, por exemplo, investiu R\$ 13,2 bilhões na mobilidade estudantil entre 2011 e 2017 (SOCIEDADE BRASILEIRA PARA O PROGRESSO DA CIÊNCIA, 2017) e, embora tenha oportunizado intercâmbio para jovens estudarem no exterior, muitos apresentaram dificuldades relacionadas ao uso da língua inglesa. Embora capazes de se comunicar em situações cotidianas essenciais, o contexto acadêmico exigia que estivessem aptos a tomarem notas durante as aulas ou palestras e a se comunicarem com a linguagem e a terminologia apropriadas durante suas apresentações. A partir dessa experiência, conforme destacado anteriormente, o Ministério da Educação (MEC) apoiou a criação do Programa Inglês sem Fronteiras que se tornou Idiomas sem Fronteiras, ao envolver outras línguas como o alemão, o espanhol, o italiano, o francês e o português como língua estrangeira.

Neste sentido, em 2016², o Programa Idiomas sem Fronteiras iniciou o mapeamento do nível de proficiência em língua inglesa das universidades públicas brasileiras, por meio da aplicação do TOEFL. Para tanto, seguiram as distinções do Quadro Comum Europeu de Referência para Línguas (QCER), utilizado por universidades estrangeiras para comprovar o nível de proficiência dos alunos que participam de programas de mobilidade estudantil. De acordo com este quadro, os níveis A1 e A2 referem-se aos falantes de nível básico; B1 e B2, falantes independentes e C1 e C2, falantes proficientes. Para que um aluno possa ler e interpretar um texto em contexto universitário ele deveria apresentar, pelo menos, o nível B1 ou B2. Para que consiga produzir textos e se comunicar satisfatoriamente, ele deveria apresentar uma proficiência entre B2 a C2, a qual influenciará a qualidade de sua produção textual e comunicação oral em língua estrangeira. Em outras palavras, o aluno de graduação que participa de um intercâmbio universitário deve estar apto a escrever textos argumentativos, assistir a aulas e palestras e tomar notas, de modo que tais ações o habilitem a realizar uma prova do curso do qual está participando ou apresentar comunicações orais em língua inglesa. Dessa maneira, os níveis C1 e C2 são os mais apropriados.

Na UNESP, de 2017 a 2019, foram realizadas várias aplicações da prova TOEFL que, embora gradativamente reduzidas a cada ano pelo MEC, sinalizaram o nível no qual a maior parte dos alunos se encontrava, conforme os gráficos dispostos a seguir.

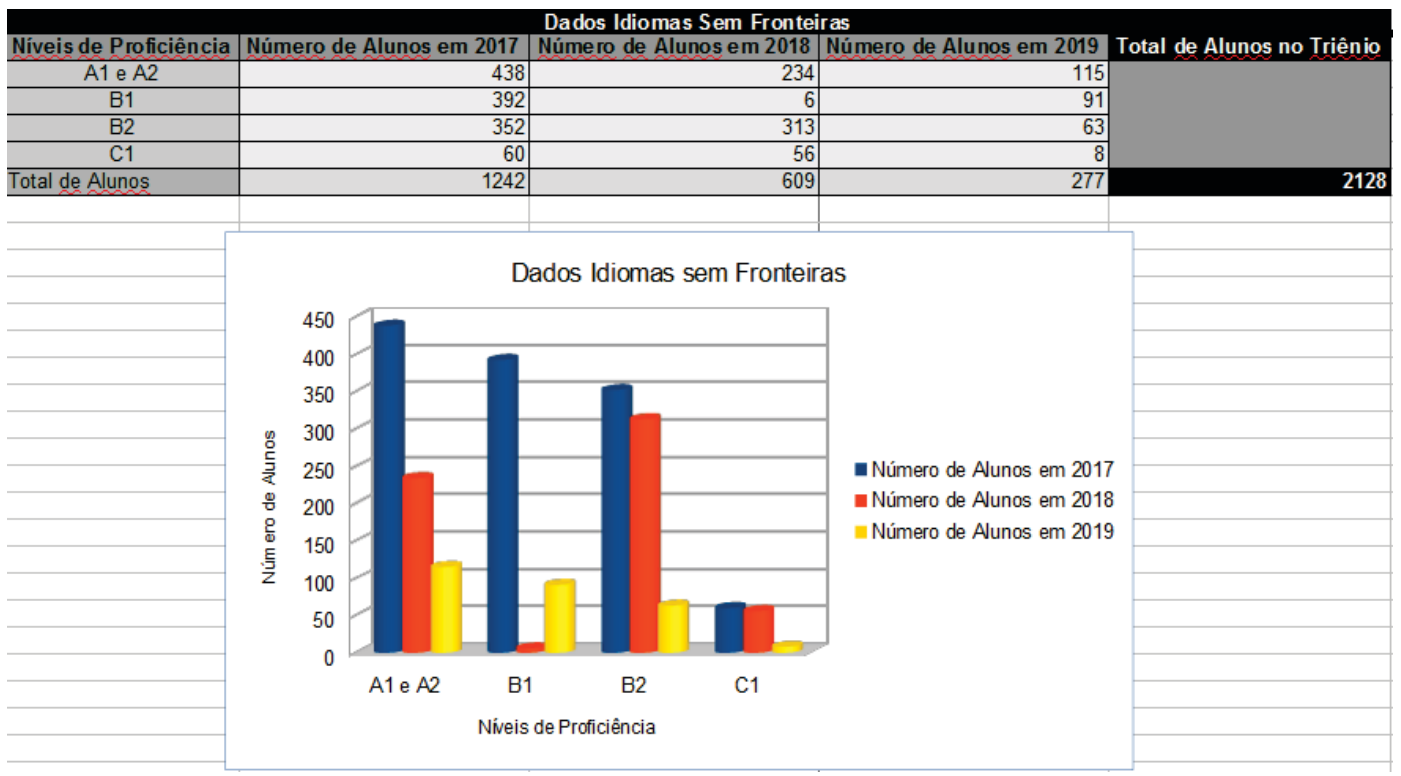

Quadro 1: Número de provas de Toefl aplicados na Unesp entre os anos de 2017 e 2019.

Fonte: Dados da plataforma IsF Gestão do Ministério

\footnotetext{
${ }^{2}$ Apesar de ter tido início em 2016, não trazemos aqui o número de provas no referido ano visto que estamos considerando os anos do Programa de Língua Inglesa.
} 
Conforme podemos notar no Quadro 1, o número de alunos, docentes e servidores que prestaram a prova do TOEFL foi diminuindo a cada ano quando o MEC passou a reduzir a cota de provas destinadas às instituições públicas. Em 2017, houve a participação de 1242 alunos, já em 2018, 609 candidatos e, em 2019, 277. Compreendemos que a diminuição de candidatos influenciou o mapeamento do nível de proficiência da comunidade unespiana, no entanto, os resultados demonstrados serviram como ponto de partida para que a implementação de ações institucionais pudesse ser feita em consonância com o Plano Estratégico de Internacionalização da UNESP.

A seguir, compartilhamos os dados levantados que ilustram melhor os níveis de proficiência observados na instituição nos três anos de participação no Programa Idiomas sem Fronteiras:
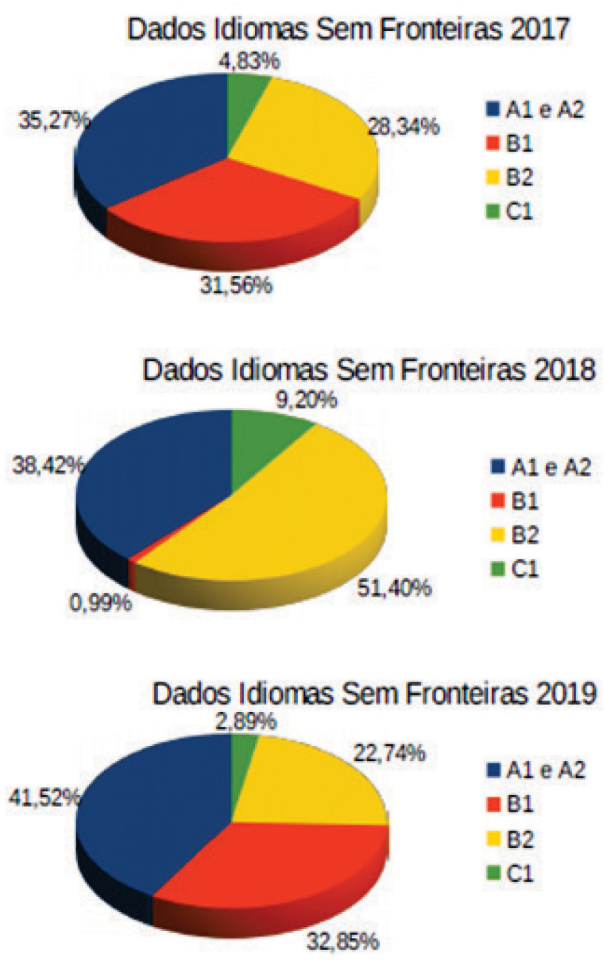

Figura 4: Mapeamento de resultados das provas de Toefl de alunos da Unesp entre os anos de 2017 e 2019.

Fonte: Dados da plataforma IsF Gestão do Ministério da Educação (2020)

Como podemos visualizar, nos três anos em que houve aplicação da prova de TOEFL na UNESP, os resultados mostraram que a porcentagem de alunos com níveis básicos de proficiência em língua inglesa variou entre, aproximadamente, 35\% a 41\%, já a porcentagem de alunos nos níveis intermediários variou entre $22 \%$ e $55 \%$ e para o nível avançado, a porcentagem variou entre, aproximadamente, $3 \%$ e $9,20 \%$.

Após estes resultados, a universidade passou a investir em ações que pudessem aumentar o nível de proficiência em língua inglesa em todos os seus setores, seja de alunos de graduação e pós, docentes e pesquisadores quanto de técnicos-administrativos. Para tanto, contou com a especialidade de docentes-pesquisadores dos três cursos de graduação e pós-graduação em Letras e Linguística para observarem mais atentamente as necessidades de cada setor. Com os resultados das provas de proficiência do TOEFL aplicadas a alunos, docentes e servidores em diferentes anos via plataforma do MEC, a UNESP passou a oferecer cursos por meio do Programa Idiomas sem Fronteiras e envolver a comunidade em outras iniciativas. Destacamos a oferta de cursos específicos para docentes da pós-graduação, para servidores dos escritórios de internacionalização dos 34 campi da UNESP e iniciativas para maior participação da comunidade em projetos que já estavam em andamento nos anos anteriores, conforme veremos mais adiante.

Envolver as pesquisas em Linguística Aplicada desenvolvidas nos programas de pós-graduação (notas 6) da UNESP foi primordial para promover um estudo mais adequado e um aprimoramento de ações. Desta forma, foi criado o Programa de Língua Inglesa da 
UNESP: internacionalização, formação e transversalidade, que conta com o apoio do convênio UNESP-Santander, para fomentar iniciativas mais robustas com vistas à melhoria da proficiência linguística na universidade.

Dentre as ações apresentadas neste artigo, duas são sobressalentes no apoio ao Plano Estratégico de Internacionalização que envolvem (a) a mobilidade virtual, no sentido de preparar, linguística e culturalmente, alunos, docentes e servidores para participarem de programas de mobilidade internacional, assim como articular um contexto adequado a estrangeiros que pretendam estudar na UNESP; e (b) a oferta de cursos presenciais e on-line como suporte para que a comunidade atinja a pontuação necessária em língua inglesa exigida em editais de internacionalização. Debruçamo-nos sobre tais ações a seguir.

\title{
2.2. AÇÕES DE MOBILIDADE E PARCERIAS VIRTUAIS
}

Iniciamos esta seção dando destaque à nossa compreensão sobre as tecnologias digitais de informação e comunicação (TDICS) no que tange ao seu uso na Educação e Ensino Superior. De acordo com Souza e Santos (2019, p.43):

\begin{abstract}
A tecnologia está ocupando cada vez mais espaço na vida das pessoas e a escola não pode ficar inerte diante dessa realidade, visto que a ideia de uma escola conectada muda a lógica de que o professor é treinado para ensinar e transmitir conhecimento. Dessa forma, o espaço escolar deve e pode se utilizar das TDICS para transformar, acompanhar o avanço da sociedade da informação e preparar os alunos para atuação no contexto social de maneira crítica e participativa.
\end{abstract}

Assim, com o suporte das tecnologias, aplicativos e mídias digitais, a mobilidade começou a ser viabilizada e potencializada na universidade, a partir das parcerias estabelecidas com instituições do exterior para o intercâmbio virtual.

Depois de uma longa trajetória de mais de uma década de ações, pesquisas e estabelecimento de parcerias, podemos mencionar o Projeto Teletandem Brasil: línguas estrangeiras para todos (TELLES, 2006, 2009, 2015) como robusta proposta para atender as demandas de acesso aos povos, línguas e culturas de forma democrática.

O teletandem pode ser definido como contexto que propicia a formação de parcerias internacionais para promover sessões bilíngues de comunicação via aplicativos como o Skype, com recursos de áudio e vídeo. Com propósitos bem delineados de aprendizagem, o teletandem permite que dois estrangeiros realizem trocas linguísticas utilizando a língua materna ou uma língua de proficiência dos pares.

Dessa forma, diferenciando-se de meros encontros com estrangeiros e com base prática e teórica, a UNESP tem desfrutado de tal possibilidade para permitir que sua comunidade estabeleça ações de mobilidade sem custos e de forma eficiente. Em vigor sob várias modalidades, integradas ou não ao currículo, é possível afirmar que uma sólida base foi construída, ao longo dos anos, com fomento da Fundação de Amparo à Pesquisa do Estado de São Paulo (FAPESP) para os campi de Assis, Araraquara e São José do Rio Preto e, em tempos atuais, apesar de encerrado enquanto projeto temático, o teletandem está instaurado como forma de reforçar contextos para ensino/aprendizagem de línguas e promover a internacionalização de maneira acessível. 


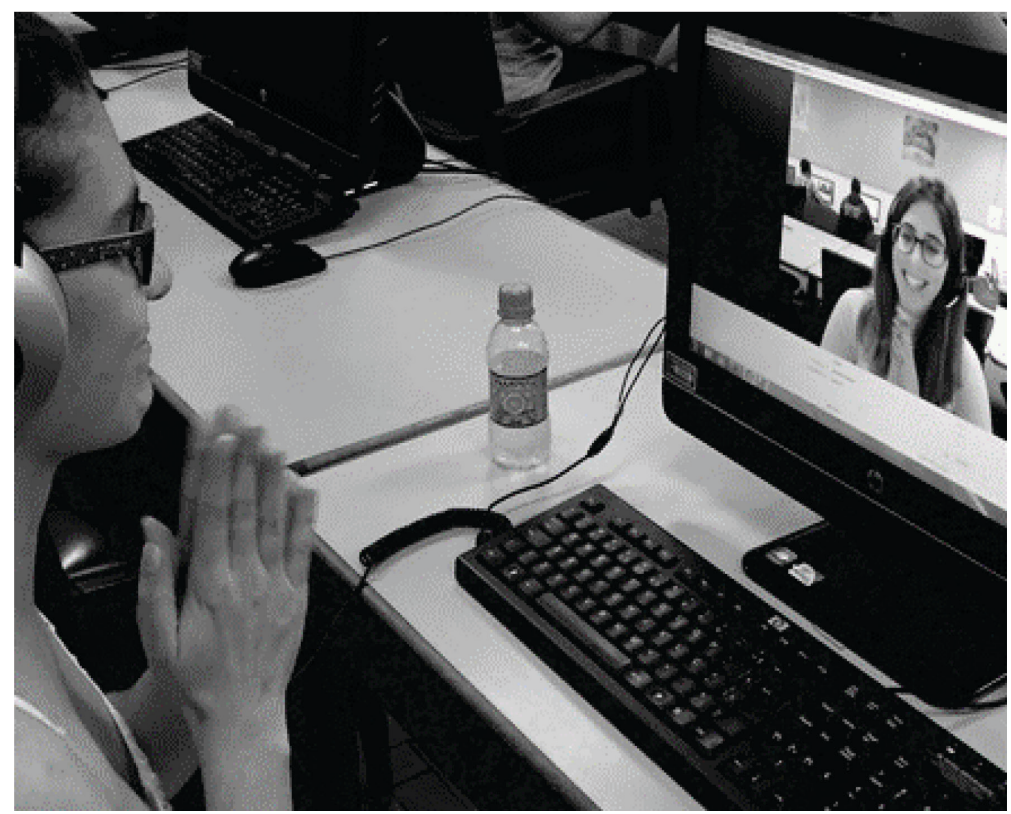

Figura 5: aluna brasileira e estrangeira em interação no projeto Teletandem Brasil

Fonte: Site do Teletandem Brasil (2020)

Atualmente, o teletandem desenvolve-se de forma intensa nos Campi de Araraquara, Assis e São José do Rio Preto, vinculado à Graduação e Pós-Graduação e, também, a toda comunidade interna, envolvendo servidores e docentes. O teletandem é definido por Telles (2015, p. 604) como "um contexto virtual, autônomo e colaborativo no qual dois falantes de línguas diferentes utilizam recursos de tecnologia VOIP (texto, voz e imagem de webcam) para ajudar o parceiro a aprender a sua língua materna (ou linguagem de proficiência)". Pautado em princípios como autonomia, reciprocidade e uso separado de línguas (SCHWIENHORST, 1998), nas ações em teletandem, os pares brasileiros exercitam a língua estrangeira e, também, auxiliam o parceiro na aprendizagem da língua portuguesa. A sessão de interação constitui-se em dois momentos dedicados à prática da língua 1 e, em seguida, da língua 2 para que, assim, cada parceiro tenha equidade de tempo e de oportunidades para desempenhar as funções de aprendiz da língua estrangeira e tutor de sua própria língua.

A partir do estabelecimento de parcerias com instituições internacionais, o teletandem tem promovido a realização de sessões bilíngues de comunicação firmadas em propósitos de aprendizagem. Considerando o período letivo dos países, o teletandem tem sido praticado, na UNESP, com países como Estados Unidos e México de forma mais intensa e observamos uma concentração das interações de fevereiro a abril e de setembro a dezembro. As interações têm a duração de uma hora e podem estar ou não associadas ao currículo, ocorrendo, também, de forma voluntária, como no Campus de Assis. Destaca-se o grande comprometimento demandado por parte das instituições já que há uma logística já desenvolvida para atender à comunidade, como, por exemplo, eficiente comunicação com a universidade parceira, organização do calendário de interações, ajustes de horários, reserva de laboratórios, testagem de programas e equipamentos, acompanhamento das sessões, suporte aos interagentes, oferta de sessões de mediação para fomentar a troca de experiências e a aprendizagem etc.

Além do teletandem, podemos mencionar as sessões de colaboração on-line estabelecidas em inglês como língua franca (ILF) entre UNESP e instituição no Reino Unido, conduzidas no Campus de Assis. ILF é um termo que tem sido utilizado por pesquisadores alinhados "[... à visão de que a língua inglesa é hoje utilizada majoritariamente em situações envolvendo falantes de diferentes línguas maternas e não exclusivamente em interações que tenham como interlocutores privilegiados os falantes nativos" (GIMENEZ et al., 2015, p. 594).

São estabelecidas parcerias entre estudantes brasileiros da UNESP e estudantes estrangeiros que se encontram na referida universidade estrangeira para abordar assuntos variados na interação ao mesmo tempo em que exercitam a língua inglesa, não nativa de nenhum dos estudantes envolvidos. Assim sendo, vários prismas se destacam na experiência transcultural como, por exemplo, 
interações síncronas pelo uso dos recursos de vídeo do Facebook, situação de igualdade ou de maior conforto perante os parceiros que são aprendizes da língua utilizada.

Uma outra forma de mobilidade virtual foi recentemente lançada na UNESP sob o nome de BRaVE, Brazilian Virtual Exchange, como estratégia de aprendizagem colaborativa on-line. Sob responsabilidade dos docentes de disciplinas de várias áreas, e com o suporte das tecnologias, parcerias são estabelecidas de forma que os alunos de instituições no Brasil e no exterior trabalhem, em suas áreas de atuação, para dividir tarefas e compartilhar conhecimento e experiências das práticas de sala de aula. Os professores de ambas as instituições se articulam e organizam tarefas a serem desenvolvidas entre os estudantes, podendo ser de forma síncrona ou assíncrona, com ferramentas e aplicativos a serem, também, negociados conforme as temáticas, abordagens ou necessidades das turmas. A ideia primordial é que a colaboração seja maximizada entre professores e entre alunos, almejando-se o desenvolvimento linguístico, profissional, intercultural e um aprimoramento e estreitamento das ações pedagógicas na universidade nas mais diversas áreas.

Ainda que com experiências incipientes, resultados positivos têm sido apontados para a ação que consta no Plano Estratégico de Internacionalização da UNESP. Segundo a coordenação, entende-se o BRaVE como atividade que promove habilidades multiculturais, aumentando a compreensão mútua com vistas à cidadania global, letramento digital e aprendizagem de línguas. Reconhecemos, assim, a iniciativa como fomentadora da internacionalização via interação no próprio país. Pelas ações iniciais em andamento, compreendemos o grande potencial para a internacionalização quando duas salas de aula são conectadas para um trabalho colaborativo, mediado pelo uso da língua como língua franca. A aprendizagem perpassa a língua, mas centra-se na temática das aulas ministradas em ambas as instituições.

Destacamos, também, a questão do comprometimento entre as instituições de modo a, por meio de atividades síncronas e assíncronas, driblar questões como diferenças de fuso- horário entre países e/ou continentes, uso de ferramentas acessíveis a ambos e o acompanhamento das ações realizadas entre os grupos de alunos.

As possibilidades de troca de conhecimento e desenvolvimento de pesquisa mediante parcerias internacionais são maximizadas com o suporte das tecnologias e de uma robusta parceria entre professores/pesquisadores que compartilham a compreensão dos grandes benefícios das ações conjuntas que envolvem a comunicação prévia entre os professores de ambas as instituições, organização do calendário de interações, agendamento de laboratórios, abertura de inscrições, dentre outros.

Destacamos, assim, o grande papel assumido pelas tecnologias que, segundo Souza e Santos (2019, p. 51) “[...] são, portanto, meios de apoio ao docente na construção do seu fazer pedagógico, transformando-se assim em instrumentos de ação.

As ações aqui descritas se alinham às afirmações de Almeida (2018, p. x) e às propostas de mobilidade e internacionalização pretendidas pela universidade.

É preciso reinventar a educação, analisar as contribuições, os riscos e as mudanças advindas da interação com a cultura digital, da integração das TDIC, dos recursos, das interfaces e das linguagens midiáticas à prática pedagógica, explorar o potencial de integração entre espaços profissionais, culturais e educativos para a criação de contextos autênticos de aprendizagem mediatizados pelas tecnologias. Para impulsionar o engajamento dos estudantes nos processos de ensino e aprendizagem é premente recontextualizar as metodologias de ensino diante das suas práticas sociais inerentes à cultura digital, ou seja, integrar as mídias e as TDIC no desenvolvimento e na recriação de metodologias ativas.

A seguir, apresentamos as ações que envolvem a oferta de cursos presenciais e on-line nos diferentes campi da UNESP. 


\subsection{CURSOS PRESENCIAIS E ON-LINE COMO PARTE DA IMPLEMENTAÇÃO DE AÇÕES EM PROL DA PROFICIÊNCIA LINGUÍSTICA}

Levando-se em consideração a real necessidade do uso da língua inglesa na universidade e o objetivo de melhorar a proficiência de seus integrantes para participação em programas internacionais, o Programa de Língua Inglesa da UNESP passou a oferecer palestras e cursos de inglês presenciais e on-line para alunos de graduação e pós, pesquisadores e servidores técnico-administrativos além de apoiar os projetos de intercâmbio virtual Teletandem Brasil e BRaVE, descritos anteriormente.

No programa, procuramos firmar acordos internos com as unidades e as Pró-Reitorias, assim como acordos externos com cursos e empresas privadas que financiam algumas ações do programa, tais como oferta de bolsas aos alunos ou apoio na preservação da infraestrutura dos laboratórios. Também participamos de editais estaduais e federais, como o do Programa Idiomas sem Fronteiras, que financiam bolsas para alunos de Licenciatura em Letras. Além disso, com o investimento na formação dos alunos de graduação de Licenciatura em Letras (cinco estrelas no Guia de Estudantes) e Pós-Graduação em Estudos Linguísticos e Literários (notas 5 e 6 na CAPES) da UNESP, e na infraestrutura dos laboratórios dos Centros de Línguas da universidade, alguns cursos do programa são desenvolvidos e ministrados nos próprios projetos de pesquisa da UNESP, como é o caso do Teletandem Brasil, que hoje é internacionalmente reconhecido e tem possibilitado oportunidades inigualáveis de contatos de alunos da UNESP com universidades no mundo todo. Experiências como estas têm possibilitado um diferencial aos profissionais formados na instituição para o mercado de trabalho.

Com este Programa, tem sido possível seguir as diretrizes da Política de Idiomas da UNESP (Resolução n.83/2016), atendendo aos princípios de democratização da educação, internacionalização e transversalidade. Neste sentido, para as ações do programa apresentadas neste artigo, temos utilizado as provas de TOEFL e, mais recentemente, as provas Aptis, do Conselho Britânico, como indicadores para acompanhar a evolução do nível de inglês de todos os alunos.

De 2017 a 2019, participamos do Programa Idiomas sem Fronteiras no qual alunos de graduação e pós-graduação em Letras e Linguística ofereceram diversos cursos de inglês com fins acadêmicos e específicos para alunos da UNESP. Com o apoio do convênio Unesp-Santander e a autorização do IsF, foi possível oferecer cursos on-line síncronos com encontros por videoconferência na plataforma Zoom, envolvendo temas como "estratégias de leitura em língua inglesa", "prática oral em língua inglesa com foco em debates" e "preparatório para TOEFL e IELTS". Aproximadamente 3.668 alunos estudaram inglês nas trinta e quatro unidades da UNESP e, em 2020, a estimativa é de termos mais 2.500 alunos com os cursos on-line de forma síncrona ${ }^{3}$.

Em 2020, último ano do programa, a Pró-Reitoria de Pós-Graduação solicitou que fosse dada ênfase aos cursos de preparatório para o TOEFL para que os alunos que participarão do programa de pesquisa e mobilidade Capes-Print (CAPES) conseguissem atingir, pelo menos, o nível B2 de proficiência exigido no edital do programa. Dessa forma, como estratégia neste ano, quatro cursos estão sendo oferecidos a alunos de pós-graduação e uma quinta turma está sendo oferecida, especificamente, aos servidores técnicoadministrativos da instituição. Durante os cursos, os alunos farão simulados para acompanhamento dos resultados e, para as notas mais altas, a prova do TOEFL ITP (Institutional Testing Program) será subsidiada pela própria universidade. A inclusão e preocupação para com os servidores técnicos-administrativos nos cursos recai na melhoria de sua proficiência linguística de modo que possam ser contemplados nos editais externos e internos para realizar visitas técnicas e treinamentos especializados no exterior.

\section{DESAFIOS E PERSPECTIVAS FUTURAS}

O mapeamento da proficiência, a aplicação de testes e oferta de mobilidade virtual sinalizam que, embora os procedimentos aqui mencionados se constituam em um grande volume de esforços conjuntos, os resultados das práticas indicam benefícios que

${ }^{3}$ Os cursos são ofertados on-line, de forma síncrona. Todavia, os alunos desenvolvem atividades de forma assíncrona com o suporte de ferramentas on-line, como o Google Classroom, por exemplo. 
extrapolam a sala de aula e os conteúdos e atingem esferas como desenvolvimento de autonomia, de competência intercultural e de formação de um cidadão para o mundo globalizado.

A universidade mostra-se, por meio de tais ações, a compreensão da internacionalização como perspectiva fundamental no cenário vigente e na formação de sua comunidade. A articulação de contextos dessa natureza reporta à ideia da inserção tão necessária e transformadora para o cenário educacional.

Percebe-se um reconhecimento maior ao trabalho e pesquisas de Linguística Aplicada desenvolvidas na UNESP, uma vez que as Pró-Reitorias têm buscado mais a participação de especialistas de línguas estrangeiras para apoiar suas ações de internacionalização ou que envolvem o ensino ou avaliação de uma língua estrangeira. Neste sentido, o apoio do Convênio UNESP-Santander tem sido fundamental para a manutenção dos bolsistas e dos laboratórios de línguas estrangeiras.

Durante os anos de 2017 a 2019, foi possível desenvolver 40 trabalhos acadêmicos no contexto do programa, quais sejam: oito apresentações acadêmicas, sete capítulos, oito artigos científicos, cinco dissertações de mestrado e duas teses de doutorado em andamento nos Programas de Pós-Graduação em Estudos Linguísticos, de S. J. do Rio Preto e Estudos Linguísticos e Língua Portuguesa, de Araraquara (6 CAPES).

No ano de 2020, sem o fomento do Programa Idiomas sem Fronteiras, a própria Pró-Reitoria de Pós-Graduação se prontificou a adquirir 300 provas de TOEFL para que alunos de pós-graduação e técnicos-administrativos possam se preparar e atingir uma melhor pontuação para participar dos editais de mobilidade.

Concluímos que o Teletandem Brasil, como ação pioneira na UNESP, apesar de não mais possuir fomento, tem ainda permitido que a mobilidade seja oferecida de forma democrática e, assim, gerado fonte de pesquisas, de aprendizagem, de crescimento e formação. Ainda como ação de mobilidade aqui mencionada, o BRaVE, também, impõe-se como iniciativa catalisadora de trocas interculturais em tempos globalizados, expandindo-se o trabalho da sala de aula e maximizando papéis de alunos e professores que, juntos, protagonizam o cenário educacional. O intercâmbio virtual coloca-se, assim, como perspectiva promissora.

Desta forma, procuramos apresentar neste artigo como o ensino/aprendizagem de línguas estrangeiras, mais especificamente o de língua inglesa, é primordial para alicerçar as estratégias de internacionalização universitária e apoiá-las com sucesso.

\section{REFERÊNCIAS}

ABREU-E-LIMA, D.M.; MORAES FILHO, W. B.; MONTENEGRO, A. R. A. Perfil da Área de Língua Inglesa nas Universidades Federais Brasileiras. In: SARMENTO, S.; ABREU-E-LIMA; D.M. MORAES FILHO, W. B. (org.). Do Inglês sem Fronteiras ao Idiomas sem Fronteiras: a construção de uma política linguística para internacionalização. Belo Horizonte: Editora UFMG, 2016. p.47-76.

ALMEIDA, M. E. B. Apresentação. BACICH, L.; MORAN, J. (org.). Metodologias ativas para uma educação inovadora: uma abordagem teórico-prática. Porto Alegre: Penso, 2018. p ix-xiii.

BELTA. Quem somos. Disponível em: http://www.belta.org.br/quemsomos. Acesso em: 26 maio 2020.

BEHRENS, M. A. Projetos de Aprendizagem colaborativa num paradigma emergente. In: Novas Tecnologias e Mediação Pedagógica, 21st ed. Papirus, 2013, pp.73-140.

BRaVE. Brazilian Virtual Exchange. Disponível em: https://www2.unesp.br/portal\#!/arex/mais-informacoes/programa-brave/ Acesso em: 30 mar. 2020. 
DE WIT, H.; HUNTER, F.; HOWARD, L.; EGRON-POLAK, E. Internationalisation of higher education. European Parliament, Directorate-General for Internal Policies, Policy Department B: Structural and Cohesion Policies, Culture and Education, 2015

GIMENEZ, T.; EL KADRI, M. S.; CALVO, L.C.S.; SIQUEIRA, D.S.P.; PORFIRIO, L. Inglês como língua franca: desenvolvimentos recentes. Revista Brasileira de Linguística Aplicada, v. 15, n.3, 2015, p. 593-619.

IDIOMAS SEM FRONTEIRAS Disponível em: http://isfgestao.mec.gov.br/ Acesso em: 30 mar. 2020.

SARMENTO, S.; ABREU-E-LIMA, D.M., MORAES FILHO, W. Apresentação. In: SARMENTO, S; ABREU-E-LIMA, D.M.; MORAES, W.M. (org.). Do Inglês sem Fronteiras ao Idiomas sem Fronteiras: a construção de uma política linguística para a internacionalização. Belo Horizonte: Editora UFMG, 2016. p. 11-15

SCHWIENHORST, K. Matching pedagogy and technology- Tandem learning and learner autonomy in online virtual language environments. Language Teaching On-Line, 1998.

SOCIEDADE BRASILEIRA PARA O PROGRESSO DA CIÊNCIA. O fim do Ciência sem Fronteiras depois de R\$ 13 bilhões investidos em bolsas no exterior. 30 jun. 2017. Disponível em: http://portal.sbpcnet.org.br/noticias/o-fim-do-ciencia-semfronteiras-depois-de-r-13-bilhoes-investidos-em-bolsas-no-exterior/. Acesso em: 30 mar. 2020.

SOUZA, F. M.; SANTOS, G. F. Velhas práticas em novos suportes? As tecnologias digitais como mediadoras do complexo processo de ensino-aprendizagem de línguas. São Paulo: Mentes Abertas, 2019.

TELETANDEM BRASIL. Disponível em: http://www.teletandembrasil.org/ Acesso em 30 mar. 2020.

TELLES, J. A. Learning foreign languages in teletandem: Resources and strategies. D.E.L.T.A., v.31, n.3, p.603-632, 2015.

TELLES, J. A. Teletandem: um contexto virtual, autônomo e colaborativo para aprendizagem de línguas estrangeiras no século XXI. Campinas: Pontes Editores/ FAPESP, 2009.

TELLES, J. A. Projeto Teletandem Brasil: Línguas Estrangeiras para Todos - Ensinando e Aprendendo línguas estrangeiras intandem via MSN Messenger. Faculdade de Ciências e Letras de Assis, UNESP. 2006. Disponível em: http://www.teletandembrasil.org/site/docs/TELETANDEM_BRASIL_completo.pdf. Acesso em: 02 jul. 2014.

UNESP. Our strategy. Disponível em: https://www.international.unesp.br/\#!/research/our-strategy/. Acesso em: 27 mar. 2020.

\section{()(1) $\circledast \circledast$}

Recebido em 31/03/2020. Aceito em 31/05/2020. 